\title{
Is autocontingency control established when a traditional contingency is simultaneously available?
}

\author{
HANK DAVIS and LACHLAN MacFADDEN \\ University of Guelph, Guelph, Ontario, Canada NIG 2 WI
}

\begin{abstract}
Using a conditioned suppression procedure, previous research has demonstrated that rats can use unsignaled shock occurrences to predict subsequent periods free from shock (Davis, Memmott, \& Hurwitz, 1975). This stimulus arrangement, termed an autocontingency (if shock, then no shock), does not exert behavioral control if a traditional tone-shock contingency is simultaneously available. The present experiment examined whether anything is learned about a simultaneously presented autocontingency, even though behavioral control is not in evidence. A transfer test revealed that exposure to simultaneous and traditional autocontingencies in Phase 1 did not result in stronger or more rapid control by the autocontingency after the traditional contingency was removed in Phase 2 . The apparent dominance of traditional over autocontingencies is discussed in terms of stimulus salience and information redundancy.
\end{abstract}

Davis, Memmott, and Hurwitz (1975) demonstrated that rats exposed to unsignaled shock deliveries were able to discriminate shock-free periods based upon constraints in the scheduling of shocks. Using a modified conditioned suppression procedure, we found that a minimum 3-min intershock interval resulted in conditioned acceleration of baseline responding immediately following each shock offset. This if shock/then no shock relationship was termed an autocontingency and is distinguished from traditional contingency relationships in which a physically different event, such as a light or tone, occurs in some contingent relationship with shock (Rescorla, 1967).

Although autocontingencies resulted in stable and reliable control of responding, their effects were not apparent whenever a traditional contingency was simultaneously available (Davis et al., 1975). In such cases, the signal-shock arrangement resulted in conventional conditioned suppression during the 1 -min tone, with no further conditioned acceleration occurring following each shock offset. All in all, our results suggest that, though responding can be controlled by either traditional or autocontingencies, control by the traditional contingency appears to exclude autocontingency control in situations where the two arrangements are simultaneously available.

A number of further experiments are necessary to explore the generality of this conclusion. In the present experiment, we were concerned with whether subjects exposed to simultaneous traditional and autocontingencies actually learned anything about the autocontin-

This research was supported in part by Grant A0673 from the National Research Council of Canada to the first author. A portion of these data was presented at the 1976 meeting of the Psychonomic Society, St. Louis, Missouri. gency even though their behavior did not reflect autocontingency control. Is the autocontingency simply "ignored" in the presence of the more informative and less subtle traditional contingency? In order to test this question, a conventional transfer design was employed. During Phase 1, one group of subjects received simultaneous traditional and autocontingency experience. A second group received only the traditional contingency. In Phase 2 , the groups were compared on the rate and degree of behavioral control exerted by the autocontingency alone.

\section{METHOD}

\section{Subjects}

Twelve experimentally naive male Long-Evans rats, 110-120 days old at the start of training, served as subjects. Each subject was maintained at approximately $80 \%$ of its free-feeding weight and housed individually with water continuously available in the home cage.

\section{Apparatus}

Subjects were run in commercially available rodent test chambers (Campden Instrument Company). Reinforcers were 45-mg Noyes pellets. The floor of each chamber consisted of 16 stainless steel grids, $.9 \mathrm{~cm}$ in diam and spaced approximately $.9 \mathrm{~cm}$ apart from edge to edge. A constant-current shock generator (Campden Instrument Company) delivered scrambled current to the grids. Shock was set at $.8 \mathrm{~mA}$ for a $1-\mathrm{sec}$ duration. The 1-min tone was provided by a Mallory sonalert (Model SC-628-H) located above the chamber within the sound-attenuating enclosure and monitored within the test cage at $90 \mathrm{~dB}$ (re: .0002 dynes $/ \mathrm{cm}^{2}$ ) in conjunction with background white noise.

\section{Procedure}

The treatment of each group is summarized in Table 1.

Prior to establishing behavioral baselines on the variableinterval (VI) 30-sec schedule of food reinforcement, all subjects received magazine and leverpress training on a continuous reinforcement schedule. All subjects received a total of 60 
Table 1

Summary of Experimental Conditions

\begin{tabular}{|c|c|c|}
\hline & Group A & Group B \\
\hline Baseline & VI 30 -sec schedule of food reinforcement & VI $30-\sec$ schedule of food reinforcement \\
\hline Phase 1 & $\begin{array}{l}\text { Traditional Contingency (if tone/then shock) } \\
\text { Autocontingency (minimum 3-min intershock interval) }\end{array}$ & $\begin{array}{l}\text { Traditional Contingency (if tone/then shock) } \\
\text { No Autocontingency (no restriction on intershock interval) }\end{array}$ \\
\hline Phase 2 & $\begin{array}{l}\text { No Traditional Contingency (tone withheld) } \\
\text { Autocontingency (minimum 3-min intershock interval) }\end{array}$ & $\begin{array}{l}\text { No Traditional Contingency (tone withheld) } \\
\text { Autocontingency (minimum 3-min intershock interval) }\end{array}$ \\
\hline
\end{tabular}

30-min sessions, at which point rates of responding on the VI 30-sec schedule were stable.

Phase 1. At the completion of baseline training, subjects were matched on their response rates and randomly assigned either to Group A or Group B. Both groups of subjects then received two sessions in which three adaptation trials to the $60-\mathrm{sec}$ tone were presented while subjects worked for food. For the balance of Phase 1, all tones terminated with shock for both groups.

Subjects in Group A $(\mathrm{N}=6)$ received three tone-shock pairings per session, with a minimum 3-min time period between shocks (the autocontingency). Subjects in Group B $(N=6)$ were presented with three tone-shock presentations per day, with no restriction on intershock interval. Tone-shock presentations for both groups were scheduled to occur at varying times within the session. Phase 1 was completed after 35 daily sessions.

Phase 2. This phase consisted solely of autocontingency training. Both groups of subjects received the same treatment.
Three shocks were programmed during each session, with a minimum intershock interval of $3 \mathrm{~min}$. The tone was not presented during this phase. All subjects were run for 35 sessions.

\section{RESULTS}

To determine the degree of control exerted by the traditional and autocontingencies, $\mathrm{A} /(\mathrm{A}+\mathrm{B})$ ratios were computed. In the ratio for traditional contingency control, A equals the response rate during the 1-min tone prior to shock. For the autocontingency ratio, A equals the response rate in the 1 -min period following shock. For both ratios, B equals the response rate in the remaining minutes of the session. Using this formula, no differential effect of the tone on baseline responding

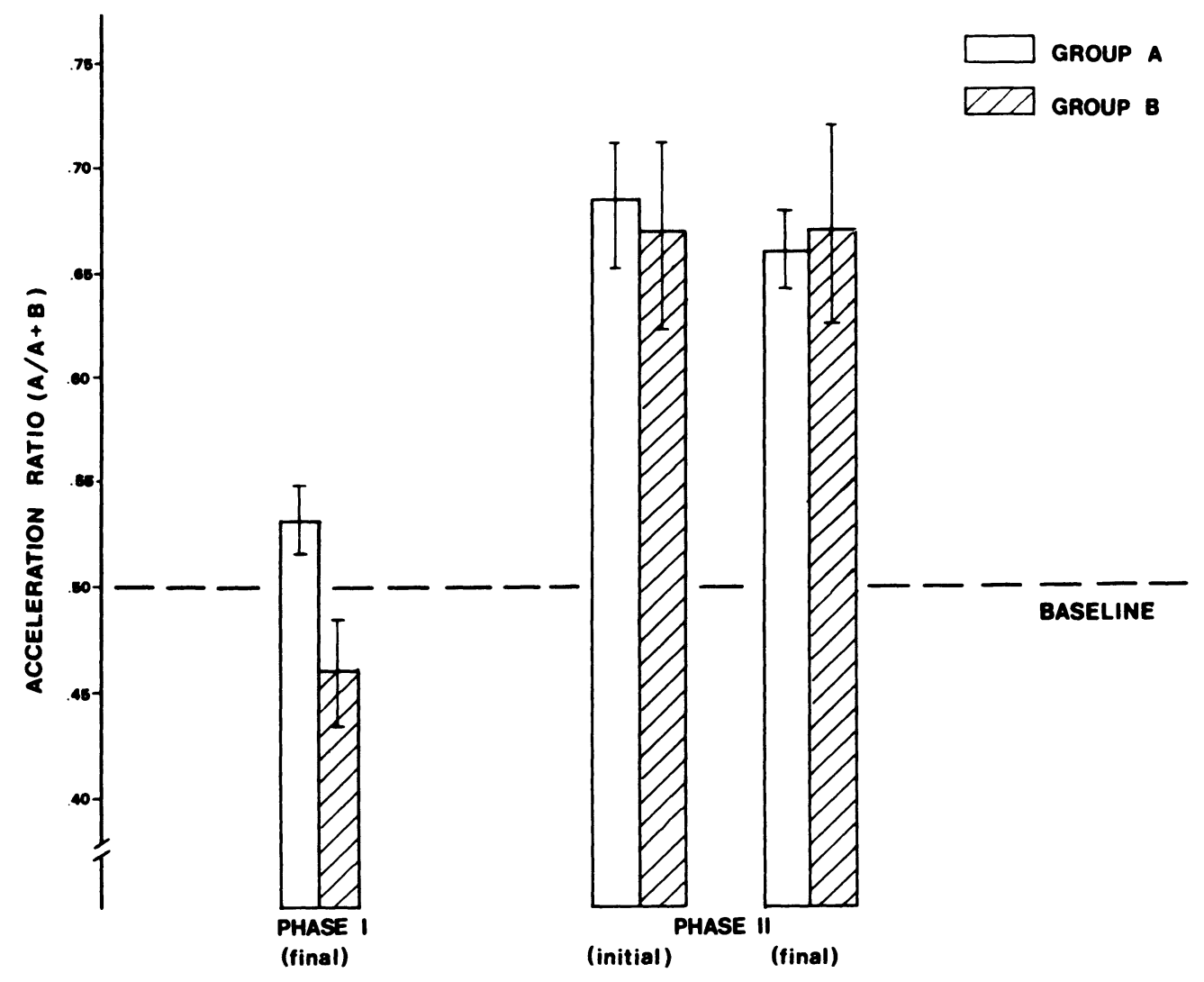

Figure 1. Degree of control by autocontingency (minimum 3-min intershock interval) expressed as an acceleration ratio $[A /(A+B)]$ of responding in a 1 -min period following shock offset. Data are reported for final and initial 10-session blocks. Vertical bars represent standard errors of the mean. 
appears as a ratio value approximating .50; conditioned suppression is indicated by values between 0 and .50 and conditioned acceleration by values between .50 and 1.00 .

\section{Traditional Contingency Control}

All subjects in both groups showed clear indication of conditioned suppression to the tone during Phase 1. There was no difference in the level of control exerted by the tone (mean suppression ratios for final 10 sessions were .03 and .04 for Groups A and B).

\section{Autocontingency Control}

If the minimum 3-min intershock interval established "safe periods" for responding, an accelerated response rate should occur immediately following each shock. The effects of the autocontingency are presented in Figure 1. There was no evidence of autocontingency control in Phase 1 , as Group A subjects received ratio scores averaging .53 over the final 10 sessions. Group B, for which no autocontingency was programmed in Phase 1 , received ratio scores averaging .46 during control recordings. These values did not differ from each other.

Behavioral control by the autocontingency was in evidence early in Phase 2, as mean ratios for the first 10 sessions rose to .68 and .67 for Groups A and B, respectively. The rate at which this control was established over sessions did not differ between groups. Ratio values did not change appreciably across the remaining sessions in Phase 2 and averaged .66 and .67 over the final 10 sessions (Groups $A$ and B, respectively).

\section{DISCUSSION}

Although previous research has demonstrated that control by traditional contingencies predominates in situations involving the simultaneous presence of an autocontingency (Davis et al., 1975), it remained to be tested whether subjects had learned anything about the autocontingency, despite the fact that it exerted no behavioral control. The present experiment examined whether autocontingency experience in Phase 1 with a traditional contingency simultaneously present had any effect on the development of control by the autocontingency alone during Phase 2. The results indicate that neither the degree of behavioral control by the autocontingency nor the rate at which it was established were affected by such Phase 1 experience.

Why Group A's prior experience with the autocontingency did not reveal itself in terms of more rapid or stronger behavioral control in Phase 2 remains a question. Assuming that the Phase 2 situation provided the opportunity for prior autocontingency learning to translate itself into behavioral terms, we must conclude that such learning was not in evidence. In short, the present results suggest that control by the autocontingency during Phase 1 was somehow blocked or overshadowed by exposure to a stimulus arrangement that was both more salient in its components and more informative with regard to shock occurrence. The importance of both of these factors has been identified in compound conditioning situations (Kamin, 1969). Further research is presently under way to determine the relative contribution of stimulus salience and information redundancy to the hierarchy of behavioral control which occurs when traditional and autocontingencies are simultaneously available.

\section{REFERENCES}

Davis, H., Memmotr, J., \& Hurwitz, H. M. B. Autocontingencies: A model for subtle behavioral control. Journal of Experimental Psychology: General, 1975, 104, 169-188.

KAmin, L. J. Predictability, surprise, attention and conditioning. In B. A. Campbell \& R. M. Church (Eds.), Punishment and aversive behavior. New York: Appleton-CenturyCrofts, 1969.

Rescorla, R. A. Pavlovian conditioning and its proper control procedures. Psychological Review, 1967, 74, 71-80.

(Received for publication February 16, 1978.) 